\title{
Frontières
}

\section{Quelques réflexions de... Sergio Kokis}

\section{Sergio Kokis}

Volume 12, numéro 1, automne 1999

Suicides, générations et culture

URI : https://id.erudit.org/iderudit/1075920ar

DOI : https://doi.org/10.7202/1075920ar

Aller au sommaire du numéro

Éditeur(s)

Université du Québec à Montréal

ISSN

1180-3479 (imprimé)

1916-0976 (numérique)

Découvrir la revue

Citer ce document

Kokis, S. (1999). Quelques réflexions de... Sergio Kokis. Frontières, 12(1),

102-102. https://doi.org/10.7202/1075920ar d'utilisation que vous pouvez consulter en ligne.

https://apropos.erudit.org/fr/usagers/politique-dutilisation/ 


\section{Quelques réflexions de... Sergio Kokis}

écrivain et peintre

Je ne crois pas qu'il y ait un «problème du suicide au Québec», ni d'ailleurs nulle part au monde. Ne confondons pas les choses. La malaria, le sida, la famine ou la prostitution infantile, entre autres, sont de vrais problèmes sociaux... Quant au suicide, il me semble qu'il est le fruit d'une prise de conscience accrue de notre propre individualité face au monde. Ceci est arrivé depuis que l'être humain jouit de suffisamment de loisir pour se pencher sur soi. Les gens se suicident moins dans les pays pauvres parce qu'ils ont des préoccupations plus pressantes; la simple survie y est déjà une forme d'aventure. En outre, les questions personnelles y trouvent encore écho dans la réponse collective donnée par la religion, par les coutumes et par une idéologie familiale (ou tribale, ou raciale, nationaliste, etc.) Une fois que les besoins essentiels sont assurés, l'être humain peut s'observer selon des perspectives multiples, personnalisées. La plupart des individus assument alors la vie sous la forme d'aventure intéressante, ne serait-ce que par simple habitude ou par curiosité à l'égard du lendemain. Quelques-uns se rendent compte qu'ils sont dans des situations extrêmes, desquelles ils n'arriveront pas à sortir, et ils décident d'abréger leurs souffrances ou ce qu'ils perçoivent comme un avilissement. D'autres encore, en général les plus jeunes, sont trop craintifs devant la vie, trop peu flexibles ou trop peu aventureux, et ils refusent le risque d'une longue existence médiocre en optant pour une sortie éclatante et immédiate. On peut agencer à l'infini ces diverses variables pour cerner les cas particuliers.

L'homme qui se tue pose nécessairement un geste moral par rapport à sa vie, à sa personne et au monde tel qu'il le conçoit. C'est là le droit et le plus fondamental d'un être humain, car c'est par la fin que la vie cesse d'être possibilité de liberté et devient sens global d'un récit fermé. Les commentaires au sujet du mort ne le concernent pas, ils sont uniquement l'expression de l'angoisse des vivants à propos de leurs vies respectives. Le mort a tiré ses propres conclusions et, quelquefois, par le suicide, il a osé enfin prendre une position devant sa vie.

Si on voulait changer les choses, en particulier pour les très jeunes gens, il faudrait être capable de leur instiller davantage de sens de l'aventure, d'amour du risque, au lieu de se contenter de la lâcheté de la morten-vie, de la trivialité et de l'imaginaire de pacotille qui caractérisent tant d'existences humaines. Est-ce possible dans des cas individuels? Sans doute. Mais étendre cela à une société serait utopique. 